\title{
Traffic Law Enforcement
}

Why traffic law enforcement?

Most drivers involved in traffic crashes do not comply with speed limits, blood alcohol levels and/or the EU-wide obligation to wear safety belts. These are the three most important factors contributing to traffic deaths and injuries in Europe.

- Drivers with BAC levels over the legal limit cause at least 6,800 road deaths every year in the EU'

- Drivers exceeding the speed limit cause about one third of all fatal and serious accidents?

- More than half of the 22.500 car occupants killed in the EU every year could survive the crash if they were wearing their seat belt. ${ }^{3}$

Safety rules have been adopted to guide drivers in their behaviour. Many road users comply with them willingly. Many others, however, would not comply if it were not for fear of being detected and punished. This is where traffic law enforcement comes in.

\section{How does it work?}

Enforcement is a means to prevent accidents from happening by way of making drivers comply with the safety rules. It is based on giving drivers the feeling that they run a too high risk of being caught and punished when breaking the rules. Efficient enforcement strategies are therefore not in the first place about increasing the actual number of controls, but about increasing the risk of being caught as perceived by the drivers.

How effective is police enforcement in Europe? If enforcement is there primarily to put drivers off committing safety offences, then current strategies are in many cases missing their goal. In most EU countries, both the subjective and objective risk of detection is very small.

In relation to alcohol for example, more than two thirds of European drivers feel they will "never" or "rarely" be checked according to a recent EU survey. The actual probability of being breath-tested is also very low. ETSC estimates that, on average, 1 in 16 inhabitants are tested every year in the EU. ${ }^{5}$

\section{Why should it be improved?}

While education and engineering improve safety in the longer term, effective enforcement leads to a rapid reduction in deaths and injuries.
IN FRANCE, the number of road deaths dropped by $20,9 \%$ in 2003 , compared with the year 2002. The most important measure taken in that year was the improvement of speed and seat belt enforcement, accompanied by an increase in penalties and strong media coverage.

- Sustained intensive enforcement that is well explained and publicised also has a long-lasting effect on drivers' behaviour.

IN FINLAND, the police has pursued a systematic DUI (= driving under influence) surveillance for over a quarter of a century. The number of those caught for drunk driving has fallen during the past 10 years from $0.33 \%$ to $0.14 \%$.

- Traffic law enforcement is a very cost-effective means of enhancing road safety. The benefits of applying existing best practice in enforcement to the whole of the EU exceed the costs by a factor of 4 (drink driving) to 10 (seat belt use)?

- Traffic law enforcement is supported by a large share of the European public. $70 \%$ of European drivers are (strongly) in favour of more enforcement of traffic laws, according to an EU survey carried out in 1996-97.

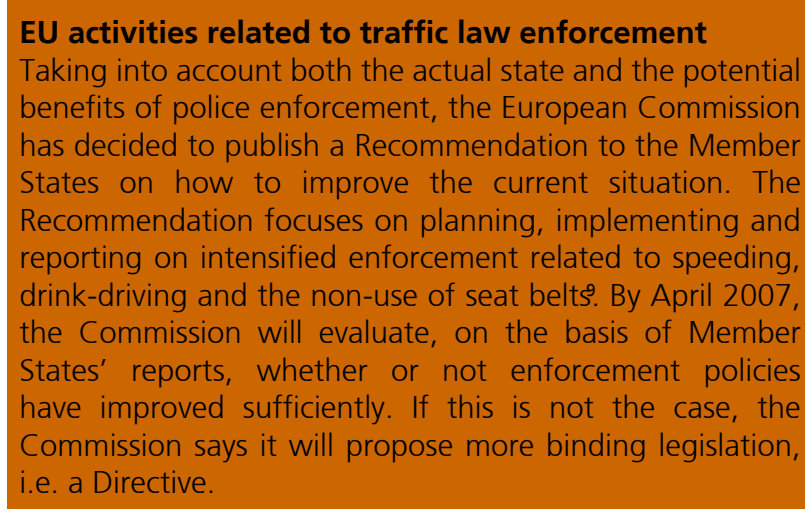

How can traffic law enforcement be improved?

Indicators and targets to plan and evaluate actions To better plan, monitor and evaluate enforcement actions, behaviour performance indicators should be used that are related to the three key areas of road user behaviour: blood alcohol level, speed and use of seat beltsio

The use of such indicators requires specially designed monitoring systems to survey these aspects of road user behaviour. The experience in countries that have set up such systems shows that policymakers are more engaged with their policies if indicator data are reported to them regularly. 
IN FINLAND, scientific monitoring of drink driving has been carried out since 1979. Regular tests produce data on the number of breath tests carried out, the proportion of drivers under the influence of alcohol and the proportion of drivers under the influence of alcohol involved in serious traffic accidents.

IN THE NETHERLANDS, a speed monitoring system collects data on average speed, standard deviations and proportions of speeding at about 400 locations divided by road category.

On the basis of previous developments of behaviour performance indicators, as well as detailed crash data, countries should set up long-term targets related to these indicators.

BELGIUM aims to bring up the percentage of drivers and front seat passengers using their seatbelts to $67 \%$ in 2005 , and to $87 \%$ in 2009

Once targets have been established, progress can easily be evaluated. This should be done in addition to an evaluation based on the basic safety indicators concerning numbers of killed and injured.

\section{Smooth procedures to follow up all offences}

All violations detected must result in a fine or punishment. To make this possible, even if large numbers of offences are detected through automated equipment, countries should adapt their legal systems. For less serious offences, administrative procedures should be applied so that detection, prosecution and sanctioning are combined into one single stage.

IN THE UK most road offences are part of the criminal code, but simplified procedures allow part of them to be treated in a mostly administrative way.

THE NETHERLANDS have gone one step further in that most offences are processed under administrative law, mainly on the ground of owner liability. This has led to an increase in penalty notices being issued but also a drastic decrease of appeal cases and of cases being dropped because of procedural errors.

Publicity to increase awareness and acceptance To make sure drivers are aware of the likelyhood of being caught in controls, enforcement actions must go hand in hand with intensive and continuing publicity, both in the media and on the roadside.

\section{Drink driving: random breath testing}

To enforce blood alcohol levels, the police should use random breath testing. This means that large-scale actions should be carried out in which all cars at a certain stretch are systematically stopped and their drivers tested, whether there is a suspicion or not. This type of testing should be carried out preferably, but not only, at times and places where drinking drivers are likely to be found, e.g. on Friday and Saturday nights. The testing frequency should amount to at least 1 test per 16 inhabitants (the current EU average) in every Member State.1

\section{Speeding: safety cameras}

Speed cameras have proven to be a very useful tool to enforce speed limits. UK studies have shown that during two years a $\mathbf{3 5} \%$ reduction in people killed and seriously injured can be achieved at camera sites, compared to the long-term trend. A long-term study carried out over a period of twelve years has concluded that cameras can reduce collisions involving injury by an astounding $46 \%$.

\section{Seat belt use: separate 'blitz' enforcement}

Currently, seat belt enforcement either results from routine general surveillance or is a by-product of the enforcement of some other law. Actions should be carried out separately, and they should be intensive, highly visible and well publicised. Studies have shown that repeated 'blitz' actions, lasting only one to four weeks, can be very effective. ${ }^{13}$

\section{Are there alternatives to police enforcement?} Intensive police enforcement swallows a lot of precious resources of both the police force and legal authorities. In the future, other compliance enhancing tools could be used more extensively. Cars and roads could be designed in such a way that the opportunities for drivers to commit errors and traffic law offences are limited.

\section{A scenario: Intelligent enforcement}

Self-enforcing cars are fitted with different technologies that assist the driver and other occupants in respecting all sorts of safety rules. In a first period, devices are used that detect offences and provide feedback to the driver (e.g. audible seat belt reminders). When sufficient public acceptance has been achieved, devices are introduced that actually limit drivers' options of committing traffic law offences (e.g. intelligent speed adaptation, ISA, and ignition interlock systems). ${ }^{14}$

Self-enforcing roads help drivers stick to the legal speed limit by indicating the appropriate speed for different stretches of road. Their design is based on a road hierarchy according to function.

\section{References}

ETSC (2003): Cost-effective EU transport safety measures

2 ETSC (1995): Reducing traffic injuries resulting from excess and inappropriate speed

3 ETSC (1999): Police enforcement strategies to reduce traffic casualties in Europe

4 SARTRE 2 (1998): The attitude and behaviour of European car drivers to road safety. Report on principal results

$5 \operatorname{ETSC}(2003)$, see note (1)

6 ESCAPE (2002): Traffic enforcement in Europe: effects, measures, needs and future. Final report of the ESCAPE consortium

7 ICF Consulting (2003): Costs-benefit analysis of road safety improvements. Final Report

8 SARTRE 2, see note (4)

9 Commission Recommendation of 6 April 2004 on enforcement in the field of road safety (2004/345/EC)

10 ETSC, ACPO and TISPOL position on the Commission Recommendation on enforcement in the field of road safety (January 2004)

11 ETSC (2003), see note (1)

12 PACTS (2003): Speed cameras. 10 criticisms and why they are flawed.

13 ETSC (1999), see note (3)

14 ETSC (2003), see note (1) 